\title{
Caracterização da oferta de suvenir nos principais atrativos turísticos da cidade de São Paulo (São Paulo, Brasil)
}

\section{Characterization of the souvenir offer on the main tourist attractions in the city of São Paulo (São Paulo, Brazil)}

\author{
Daiana Machado dos Santos (SANTOS, D. M. dos)
}

RESUMO - O suvenir é um componente importante da experiência turística, pois a maioria dos turistas trazem de volta lembranças e recordações como memória de suas experiências. Partindo das inquietações referentes à existência ou não de um suvenir característico da cidade de São Paulo (São Paulo, Brasil), pareceu relevante, tanto do ponto de vista da teoria quanto do ponto de vista do mercado, analisar a oferta de suvenir nos principais atrativos turísticos da cidade. $O$ estudo teve como objetivo específico a caracterização dos produtos oferecidos com relação à tipologia, procedência, referência externa e temática e discutir a relação entre os suvenires oferecidos nos principais atrativos da cidade de São Paulo como destino turístico. Tratase de um estudo exploratório-descritivo, realizado mediante revisão bibliográfica para a construção do arcabouço teórico e conceitual orientador do trabalho, bem como levantamento in loco da oferta de suvenir nos seis principais atrativos turísticos, selecionados a partir do Guia 4 Rodas Brasil 2014, correspondente a última edição antes da elaboração pesquisa.

Palavras-chave: Turismo; Oferta turística; Atrativos turísticos; Suvenir.

ABSTRACT - The souvenir is an important component of the tourism experience, as the most tourists use to carry back memories and memorabilia as proof of their experiences. Based on the concerns regarding the existence of a characteristic souvenir from São Paulo city, it seemed relevant, both from the point of view of theory and market, to analyze the souvenir's offer on the main tourist attractions in the city of São Paulo. The study had the objective to characterize the products offered in relation to the type, origin, external reference and thematic and also to discuss the relationship between the souvenir offered and the main attractions in the city of São Paulo as a tourist destination. This is an exploratory-descriptive study that was conducted through literature review for the construction of the theoretical and conceptual framework guiding the work as well as on-site survey of the souvenir offer in six major tourist attractions, selected from the "Guia 4 Rodas Brasil 2014", corresponding to the last edition before to the elaboration of the research.

Key words: Tourism; Tourist offer; Tourist attractions; Suvenir.

\footnotetext{
* Formação: Graduada em Tecnologia em Gestão de Turismo pelo Instituto Federal de Educação, Ciência e Tecnologia de São Paulo, Campus São Paulo. Atividade profissional: Docente de Educação Física Secretaria de Educação do Estado de São Paulo. Endereço físico para correspondência: Rua Antonieta Aguirre de Moraes Barros, 88 (Vila Augusta). CEP: 07025011 - Guarulhos - São Paulo/SP - Brasil. E-mail:daiana-agape@hotmail.com
} 


\section{INTRODUÇÃO}

O turismo é um fenômeno marcado pelo consumo, seja de bens materiais ou imateriais. Colaborando para isso, a oferta de suvenir é observada nos destinos turísticos, especialmente em atrativos com grande fluxo de visitantes. É durante as viagens que o turista adquire suvenir que o permite levar para casa um pouco do que foi visitado durante a viagem. Considerando a compra de suvenir onde o turista experencia o espaço turístico, a motivação para o consumo destes produtos pode ter um significado maior. Muitas vezes, essa mercadoria comum, vista como uma "lembrançinha" está repleta de significados e torna tangível aquilo que é imaterial no turismo. Um dos principais objetos de consumo constitutivos da experiência do turista, o suvenir pode ser entendido como qualquer produto consumido pelas pessoas durante as suas experiências turísticas em lojas e outros espaços destinados a este fim ou aquilo que o viajante traz consigo do local visitado. (HORODYSKI; MANOSSO; GANDARA, 2012, 2014; MACHADO; SIQUEIRA, 2008).

Embora o suvenir seja muito presente nas viagens e represente materialmente o vínculo entre o lugar visitado e o lar para o qual se retorna, existem poucos estudos sobre o tema (HORODYSKI; MANOSSO; GANDARA, 2012). Siqueira e Machado (2008) apontam que "o suvenir permeia estudos nos campos da cultura, do consumo, mas não costuma ser objeto de investigação". Um dos motivos pode ser devido a esse objeto ser considerado banal, de baixo custo, consumido massivamente pelos visitantes, visto de forma pejorativa, gosto duvidoso ou até mesmo sem um significado ou função concreta (HORODYSKI; MANOSSO; GANDARA, 2012, 2014; MACHADO; SIQUEIRA, 2008). Outra possível explicação pode ser a associação do suvenir com fatores de descaracterização da cultura local (RUSCHMANN, 1999). Panosso Netto (2005) destaca que os suvenires são considerados com pouco valor cientifico o que acaba por não atrair o desejo de pesquisa.

A despeito disso tudo, o estudo de suvenir apresenta grande possibilidade de pesquisa, com oportunidade de análise, primeiramente pelo desejo de consumo do turista, depois por serem bens que representam o espaço visitado (SWANSON, 2004).

A cidade de São Paulo, segundo o Observatório de São Paulo (2014), recebeu os prêmios de melhor destino turístico $\left(1^{\circ}\right.$ lugar $)$ e de melhor destino da America do Sul ( $3^{\circ}$ 
lugar) além de apresentar como principais motivações de seus visitantes o entretenimento (57\%). Contudo, em geral, verificou-se não haver um suvenir típico para a cidade. Também se constatou existir poucas pesquisas que investigaram a caracterização da oferta de suvenir nos atrativos turísticos e sua ligação com São Paulo.

Diante desse contexto, parece relevante, tanto do ponto de vista da teoria quanto do ponto de vista do mercado, o que se propõe como objetivo deste artigo: analisar a oferta de suvenir nos principais atrativos turísticos da cidade de São Paulo. O estudo tem como objetivo específico: caracterizar os produtos oferecidos com relação a tipologia, procedência, referência externa e temática e discutir a relação entre o suvenir oferecido.

Trata-se de um estudo exploratório-descritivo, realizado mediante revisão bibliográfica para a construção do arcabouço teórico e conceitual orientador do trabalho, bem como levantamento in loco da oferta de suvenir nos seis principais atrativos turísticos, selecionados a partir do Guia 4 Rodas Brasil 2014.

\section{SUVENIR: CONCEITOS E DIMENSÕES}

O setor turístico abrange hotéis em geral e outros tipos de acomodações, restaurantes e outros serviços, serviços e instalações ligados ao transporte, divertimentos, atrações e instalações para o lazer em geral, lojas de suvenir e um grande número de outros empreendimentos. (THEOBALD, 2002). O turismo desponta como um conjunto de atividades que vão além dos fatores vinculados à economia, lazer e educação. O mesmo converge para ações de preservação do patrimônio cultural, resgate da memória e a valorização das manifestações culturais dos indivíduos nas sociedades. (p. 410) Porém, “o turismo está cada vez mais regulado pela lógica do mundo globalizado que, entre outros fatores, mediatiza, por meio da imagem, as culturas e a natureza, transformando-as em mercadoria" (BANDUCCI, 2002, p. 39). Assim, na sociedade contemporânea, os produtos tangíveis e intangíveis são revestidos de um simbolismo que lhes confere um valor superior ao seu valor de troca.

Segundo o Plano Nacional de Turismo, o setor do turismo é uma das atividades que mais se desenvolve no mundo (BRASIL, 2010), sendo que muitas áreas estão 
diretamente ou indiretamente relacionadas a este segmento, e o suvenir é uma delas (BRASIL, 2010).

Segundo o Dicionário Aurélio (2014), o suvenir (do francês, para lembrança) é um objeto que resgata memórias que estão relacionadas ao destino turístico; objeto característico de um lugar, vendido como lembrança a viajantes, especialmente a turistas; miniaturas de estátuas, monumentos, embarcações, obras de artes, em alusão a determinados lugares, dentre outros.

Trata-se de um objeto dotado de significado, tanto para quem o produz quanto para quem o compra; ele atua como uma forma de comunicação, de laço, de ligação com o destino visitado, representando experiências e narrativas turísticas, que funcionam como elementos que ajudam a montar o mosaico da vida, recordando as histórias que a compõem (MAFFESOLI ${ }^{1}$ apud MACHADO; SIQUEIRA, p. 2, 2014).

Como "objetos de transição", os suvenires são "pedra de toque de significado que podem evocar memórias poderosas de experiências e mediar o nosso sentido de lugar, envolvendo o passado com o presente" (MORGAN; PRITCHARD, 2005, p. 31).

O suvenir, portanto, pode ser entendido com um objeto que atende à necessidade de representar mentalmente experiências passadas e religar a pessoa ao atrativo visitado. Evoca sentimentos experimentados pelo turista na viagem, como aqueles que emergiram em suas interações com os moradores, ocorridas, por exemplo, durante as compras.

O suvenir é um componente importante da experiência turística, pois a maioria dos turistas traz de volta lembranças e recordações como prova de suas experiências. Com isso, também se configura como importante fonte de renda para artistas e pontos turísticos, além de disseminar a imagem de determinado atrativo ou destino. A partir disto, o suvenir pode ser destacado também como uma excelente oportunidade de publicidade, promovendo através de sua imagem as características de uma localidade (SOUZA; CARVALHO, 2014, p. 78).

\footnotetext{
${ }^{1}$ MAFFESOLI, M. Le temos des tribus. Le déclin de l'individualisme dans les sociétes postmodernes. Paris: La Table Ronde, 2005.
} 


\subsection{MÚLTIPLOS SIGNIFICADOS DO SUVENIR NO TURISMO}

Os autores que abordam o suvenir privilegiam determinadas óticas e perspectivas. Nunes (2010), Reis (2008), Machado e Siqueira (2008) e Medeiros e Castro (2014), abordam o suvenir sob o aspecto das representações socioculturais, entendendo que o mesmo pode representar o imaginário de uma comunidade produtora sobre o lugar onde vive, bem como corresponder às expectativas do visitante em relação à imagem turística do espaço visitado focando na produção mais artesanal de suvenir.

Swanson (2004) analisa a representação espacial do suvenir; que é compreendido como forma de preservar de maneira palpável uma experiência vivida, sendo assim uma prova tangível de que se visitou determinado espaço. São bens que representam de alguma forma o espaço visitado (SWANSON, 2004) e, finalmente, "tangibilizam" as experiências turísticas vividas neste espaço (REIS, 2008). Isso porque o suvenir não deve ser analisado pelo que parece ser, mas por aquilo que ele representa às pessoas, conforme já discutido, com base em Panosso Netto (2005). Assim, deve-se compreender que "um suvenir é um signo, um símbolo" (MACHADO; SIQUEIRA, 2008, p. 6) e por isso, faz parte das experiências dos turistas em um determinado destino.

Peach (2007) estuda a relação dos suvenires com a identidade cultural, conjunto vivo de relações sociais e patrimônios simbólicos historicamente compartilhados que estabelece a comunhão de determinados valores entre os membros de uma sociedade.

Horodyski; Morodyski; Manosso; Gandara (2013) relacionam o tema com o marketing turístico, o qual visa conhecer bem os seus clientes para que a partir disso sejam desenvolvidos produtos que venham a satisfazer suas necessidades reais e potenciais.

Para Beni (2006) os suvenires são produtos turísticos constituintes do produto turístico total, isto é: atrativos naturais, culturais e técnicos científicos; infraestrutura e serviços como estradas, portos, aeroportos, comunicações, saneamento ambiental, energia, saúde, segurança; equipamentos e serviços de hospedagem, alimentação, transporte, agências de receptivo, informação, sinalização; e entretenimento. O mesmo autor apresenta o suvenir dentro da categoria "outros serviços turísticos: comércio 
turístico" sendo "a venda de mercadorias de interesse para os visitantes, em especial aquelas que servem como lembranças da viagem" (BENI, 2006, p. 46).

No âmbito das políticas públicas brasileiras, o Ministério do Turismo (2010) reconhece o suvenir como um produto experiencial, capaz de "materializar" as situações vivenciadas pelos turistas no espaço geográfico. Também entende que o consumo de suvenir é um objeto de pesquisa repleto de oportunidades de análises, primeiramente porque, inevitavelmente, despertam desejo por parte de muitos turistas.

\subsection{TIPOLOGIAS}

Para Gordon² apud Horodyski; Manosso; Gândara (2012) os suvenires podem ser representados por uma série de objetos diferentes, categorizados em produtos pictóricos, réplicas e ícones, produtos com marca, objetos piece-of-the-rock e produtos locais (arte, artesanato, arte folclórica, produtos alimentícios e vestuário). O Quadro 1 apresenta a síntese destas características, como segue:

\begin{tabular}{|c|c|c|}
\hline TIPO & & SÍNTESE \\
\hline $\begin{array}{l}\text { Produtos } \\
\text { Pictóricos }\end{array}$ & \multicolumn{2}{|c|}{$\begin{array}{l}\text { Produtos que apresentam imagens do destino turístico, como, por exemplo, } \\
\text { cartões postais, folhetos, pôsteres, livros, dentre outros. }\end{array}$} \\
\hline $\begin{array}{l}\text { Réplicas } \\
\text { e Ícones }\end{array}$ & \multicolumn{2}{|c|}{$\begin{array}{l}\text { Bens que representam ícones dos destinos turísticos, elementos que fazem } \\
\text { parte do imaginário dos turistas, como monumentos, construções, obras de arte } \\
\text { etc., como, exemplo, miniaturas da Torre Eiffel. }\end{array}$} \\
\hline $\begin{array}{l}\text { Produtos } \\
\text { com } \\
\text { marca }\end{array}$ & \multicolumn{2}{|c|}{$\begin{array}{l}\text { Produtos que possuem a marca do destino turístico expressa em artigos } \\
\text { diversos, tais como brinquedos, canecas, adesivos, camisetas, chaveiros, ou } \\
\text { outros produtos que identifiquem a imagem turística. }\end{array}$} \\
\hline $\begin{array}{c}\text { Objetos } \\
\text { "piece-ofthe-rock" }\end{array}$ & \multicolumn{2}{|c|}{$\begin{array}{l}\text { Objetos de caráter natural em seu estado bruto, ou manufaturados, como } \\
\text { conchas, rochas, areia, flores, sementes, animais empalhados etc. }\end{array}$} \\
\hline \multirow[t]{4}{*}{$\begin{array}{l}\text { Produtos } \\
\text { Locais }\end{array}$} & Arte & $\begin{array}{l}\text { Obras produzidas por artistas locais, geralmente } \\
\text { comercializadas em galerias de arte, "feiras de artesanato" e } \\
\text { em alguns casos, nas próprias lojas de suvenir. }\end{array}$ \\
\hline & Artesanato & $\begin{array}{l}\text { Peças produzidas com fins utilitários, cujas técnicas de } \\
\text { produção acompanham gerações e fazem parte da cultura de } \\
\text { uma comunidade. Como exemplo, têm-se potes, peneiras, } \\
\text { balaios, remos, redes de pesca, objetos de couro etc. }\end{array}$ \\
\hline & Arte Folclórica & $\begin{array}{l}\text { Obras produzidas por artistas locais, cujas técnicas são } \\
\text { transmitidas por gerações e características de uma } \\
\text { comunidade. Exemplos: bonecas de barro, carrancas etc. }\end{array}$ \\
\hline & $\begin{array}{l}\text { Produtos } \\
\text { Alimentícios }\end{array}$ & $\begin{array}{l}\text { Alimentos que representam o destino turístico, consumidos } \\
\text { como lembranças do local visitado. Podem ser } \\
\text { industrializados ou artesanais e necessitam de embalagens }\end{array}$ \\
\hline
\end{tabular}

${ }^{2}$ GORDON, B. The Souvenir: Messenger of The Extraordinary. Journal of Popular Culture, 20 (3), p. 135- 146, 1986. 


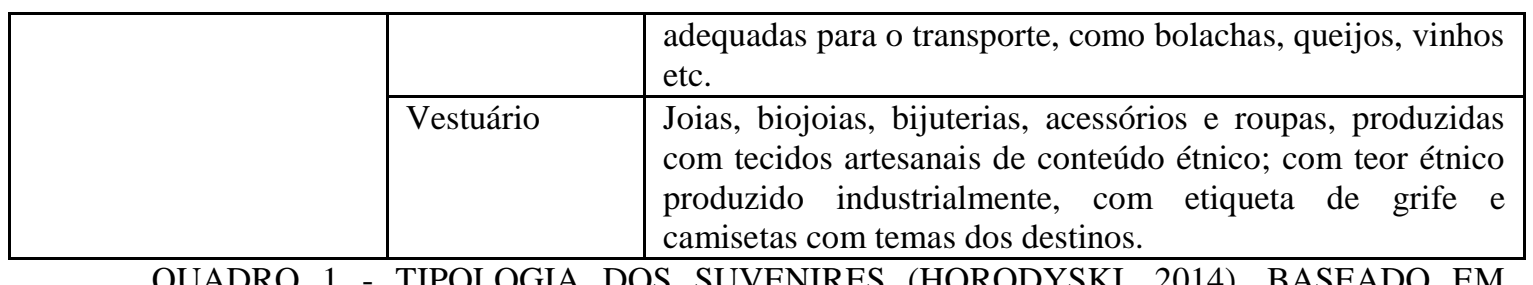

QUADRO 1 - TIPOLOGIA DOS SUVENIRES (HORODYSKI, 2014), BASEADO EM GORDON 1986.

Para Horodyski (2014) estas categorias possibilitam compreender a abrangência da variedade de artigos que envolvem este mercado e suas tipologias.

\section{O TURISMO EM SÃO PAULO}

De acordo com o Instituto Brasileiro de Geografia e Estatística - IBGE (2014) a população estimada para o município de São Paulo era de 11,9 milhões de habitantes. Segundo a SPTuris - autarquia responsável pela gestão do turismo na cidade - São Paulo apresentava mais de cem pontos turísticos, que vão de monumentos arquitetônicos, a atrações culturais e de lazer.

Além disso, a cidade de São Paulo estava oferecendo diversas atrações históricas, naturais e culturais. São 282 cinemas, 164 teatros, 125 museus e 39 centros culturais (SPTURIS, 2014) e 103 parques e áreas verdes (PREFEITURA MUNICIPAL DE SÃO PAULO, 2014).

A capital paulista é o principal centro financeiro e a maior cidade do Brasil. Oferece vários pontos de entretenimento, centros culturais, museus e parques. Segundo o Instituto Brasileiro de Turismo - EMBRATUR (2012), a cidade é o destino mais procurado pelos estrangeiros que viajaram ao Brasil a negócios, eventos e convenções, e a terceira colocada nas viagens de lazer.

Segundo o Ministério do Turismo ${ }^{3}$, em 2010 o turismo em São Paulo alcançou um novo recorde recebendo 11,7 milhões de turistas. Em 2012 foram 12,9 milhões de turistas durante o ano, sendo 10,8 milhões domésticos e 2,1 milhões de estrangeiros, consolidando-se como principal porta de entrada de estrangeiros no Brasil, os quais deixaram $\mathrm{R} \$ 10,2$ bilhões na cidade.

\footnotetext{
${ }^{3}$ BRASIL, 2010. Ministério do Turismo.
} 


\subsection{A IMAGEM DE SÃO PAULO COMO DESTINO TURÍSTICO}

Conhecida pelo senso comum como uma cidade cosmopolita que oferece o mundo aos brasileiros e, ao mesmo tempo, proporciona um gostinho do Brasil aos milhões de estrangeiros que nela chegam movidos principalmente por negócios e eventos, São Paulo não é apenas o maior centro econômico da América Latina. É a capital da cultura, da moda, do entretenimento. Metrópole antenada, que aponta tendências ${ }^{4}$. Essa diversidade, porém, pode dificultar a busca por uma imagem que direcione a venda de suvenir e consolide o destino junto ao turista. Para Caio Luiz de Carvalho, presidente da Embratur entre janeiro de 1995 e fevereiro de 2002, e exministro do Esporte e Turismo, o excesso de opções confunde e intimida o turista que, sem um foco, não consegue se identificar com o destino, impossibilitando assim que se sinta estimulado a visitá-lo ${ }^{5}$.

O suvenir é um componente importante da experiência turística, pois a maioria dos turistas trazem de volta lembranças e recordações como prova. Segundo Barbosa (2003 ${ }^{6}$ apud HORODYSKI; MANOSSO; GANDARA, 2012), o consumo não deve ser visto como um fim em si mesmo, mas, antes de tudo, como um meio. Além disso, para Maffesoli (2005) ${ }^{7}$ apud HORODYSKI; MANOSSO; GANDARA (2012), o suvenir como um objeto dotado de significado, tanto por quem o produz quanto por quem o compra, pode e atua mesmo como uma forma de comunicação, de laço, de ligação.

Considera-se poder afirmar que São Paulo é uma cidade que, com personalidade, vai encontrando sua imagem turística e cada vez mais seduz o imaginário daqueles que a visitam ao convidar o turista a interagir com o destino, com sua diversidade cultural única, a vivenciar experiências paulistanas ${ }^{8}$.

\footnotetext{
${ }^{4}$ Fonte: <http:// www.spturis.com.br $>$.

${ }^{5}$ Fonte: <http://www.spturis.com.br $>$.

${ }^{6}$ BARBOSA, M. de L. de A.; FARIAS, S. A. de. Em Busca de uma Experiência Extraordinária em Serviços de Restaurante. Rosa dos Ventos, v. 4, 2012.

${ }^{7}$ MAFFESOLI, M. Le temos des tribus. Le déclin de l'individualisme dans les sociétes postmodernes. Paris : La Table Ronde, 2005.

${ }^{8}$ Pensamento do autor.
} 


\section{A OFERTA DE SUVENIR NOS PRINCIPAIS ATRATIVOS TURÍSTICOS DA CIDADE}

Nesta pesquisa entendeu-se atrativo turístico como: “[...] todo lugar, objeto ou acontecimento turístico que motiva o deslocamento de grupos humanos para conhecêlos" $"$. Teve em vista identificar os principais atrativos da cidade, utilizou-se o referencial Guia 4 Rodas Brasil (2014) como base, selecionando todos os atrativos classificados na categoria mais elevada de atratividade: "Vale a Viagem": Catavento Cultural e Educacional, Museu da Língua Portuguesa, Museu de Arte de São Paulo MASP, Museu do Futebol, Parque do Ibirapuera e a Pinacoteca do Estado de São Paulo. Desses foram selecionados os que apresentavam ponto de venda de suvenir em suas instalações, ou seja, o Museu da Língua Portuguesa e o Parque do Ibirapuera não foram considerados. Vale destacar que dentro do Parque encontravam-se outros atrativos, dentro os quais o Museu de Arte Moderna - MAM, em que havia uma loja. Porém, o Museu estava individualmente classificado pelo Guia como um atrativo "3 estrelas: muito interessante", o que não satisfez os critérios estabelecidos para identificação dos principais atrativos da cidade.

Ainda que indiscutida a relevância do Guia 4 Rodas como indicador, e confirmado com as indicações no Trip Advisor e no site da SPTuris, levou-se em conta que, o critério de metodologia para a seleção dos atrativos apresentava limitações, pois se configurava como único parâmetro para desenvolvimento desta pesquisa.

Na primeira quinzena de novembro de 2014, foram feitas visitas às lojas dentro dos atrativos, nos dias e horários de funcionamento ao público, em que se buscou levantar quais produtos estavam sendo oferecidos como suvenir, preço, características e relação com o destino ou o atrativo. Para a representação foram utilizadas tabelas e definições adaptadas de $\operatorname{Gordon}^{10}$ apud HORODYSKI; MANOSSO; GÂNDARA, 2012).

\footnotetext{
${ }^{9}$ EMBRATUR 1984.

${ }^{10}$ GORDON, B. The Souvenir: Messenger of The Extraordinary. Journal of Popular Culture, 20 (3), p. 135- 146, 1986.
} 


\subsection{CATAVENTO CULTURAL E EDUCACIONAL - ORGANIZAÇÃO SOCIAL DE CULTURA}

O prédio que estava abrigando o Catavento, localizado no Parque Dom Pedro II, no centro de São Paulo, foi construído inicialmente para servir para exposições abertas ao público, porém teve outras finalidades e foi ocupado como presídio, Assembleia Legislativa, sede da Prefeitura e Palácio das Indústrias. Finalmente, o espaço volta à sua ideia inicial, ou seja, tornou-se espaço de iniciação científica aberto para crianças, jovens e adultos de terça a domingo, das $9 \mathrm{~h}$ às $17 \mathrm{~h}$.

São 8 mil metros quadrados de exposição, com 250 instalações divididas em 4 seções: Universo, Vida, Engenho e Sociedade. Em todas as instalações verificou-se estarem sendo utilizados vídeos, painéis e maquetes como suporte didático, mas o que se considerou mais importante foi a possibilidade de interatividade que alguns apresentavam.

Fundado em março de 2009, estima-se que o Catavento estivesse recebendo, por ano, cerca de 600 mil pessoas (CATAVENTO CULTURAL, 2014), entre elas, alunos e professores que usavam o espaço como ferramenta de complemento às atividades da escola.

\subsubsection{Loja}

Primeiro atrativo listado pelo Guia 4 Rodas (2014) na categoria Vale a Viagem, recebeu sua loja com o objetivo de vender os experimentos que apresentassem os mesmos conceitos científicos das grandes máquinas expostos no atrativo. Considerou-se serem ideais para o ensino da ciência, por serem facilmente transportados e montados para serem aplicados durante uma aula.

A loja estava localizada no piso térreo, ao lado do Café Lua e em frente à seção Vida. A loja era toda acessível aos visitantes, que podiam testar os experimentos. A mesma era terceirizada pela empresa Ciência Prima, a qual estava oferecendo produtos voltados para os experimentos do museu. Cada kit estava acompanhado de uma explicação de seu funcionamento e o conceito científico envolvido. Abaixo, expressos no Quadro 2 foram descritas as mercadorias. 


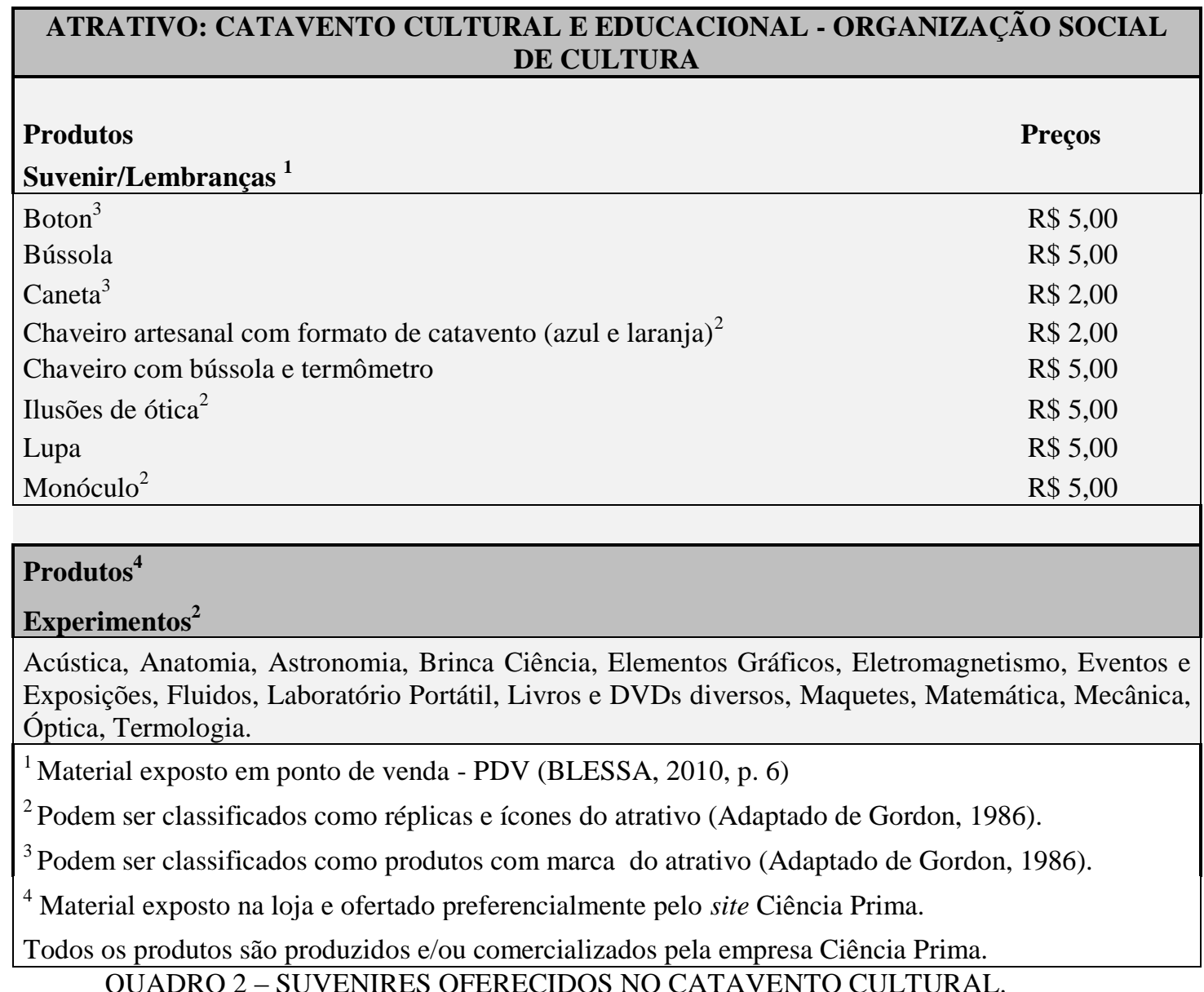

\subsection{MUSEU DE ARTE DE SÃO PAULO ASSIS CHATEAUBRIAND - MASP}

Dono do edifício cartão postal da cidade, o Museu de Arte de São Paulo tem seu acervo tombado pelo Patrimônio Histórico e Artístico Nacional - IPHAN desde 1969 e em 1982 foi tombado pelo CONDEPHAAT - Conselho de Defesa do Patrimônio Histórico, Arqueológico, Artístico e Turístico do Estado e em 2003 pelo IPHAN Instituto do Patrimônio Histórico e Artístico Nacional ${ }^{11}$. Contava com cerca de 8.000 peças, dentre as quais se destacavam as pinturas ocidentais, principalmente italianas e francesas.

Estava sendo o museu mais frequentado de São Paulo, com média de 50.000 visitantes/mês foi fundado em 1947, o Masp foi idealizado por Assis Chateaubriand, empresário e jornalista, e Pietro Maria Bardi, jornalista e crítico de arte italiano ${ }^{12}$. Como

\footnotetext{
${ }^{11}$ MASP - Museu de Arte de São Paulo. Sobre o Masp.
} 
São Paulo era na época a grande capital financeira, principalmente devido a circulação do dinheiro das indústrias e do café, decidiu-se que o Masp seria construído nesta cidade (MASP, 2014).

A nova sede, na próspera Avenida Paulista, foi projetada por Lina Bo Bardi. Foram 12 anos entre projeto e execução ${ }^{13}$. Lina trabalhou sob uma condição imposta pelo doador do terreno à prefeitura de São Paulo: a vista para o Centro da cidade e para a Serra da Cantareira teria de ser preservada, através do vale da Avenida 9 de Julho ${ }^{14}$. Assim nasceram as quatro colunas do atual museu com um vão livre de 74 metros, nascendo um dos cartões postais da cidade de São Paulo, foi inaugurado em $1968^{15}$.

Como o prédio foi projetado suspenso pelas quatro colunas e a vista da Paulista para o centro da cidade fosse preservada, foi concebida uma esplanada abaixo do edifício $^{16}$. As colunas do edifício foram pintadas de vermelho somente em 1990 na ocasião dos 40 anos do museu, obedecendo ao projeto original ${ }^{17}$. Na reforma de 1997 , o prédio recebeu um terceiro andar subsolo, onde se encontrava a reserva técnica, moderno espaço que abrigava as peças do acervo enquanto não estavam em exposição ${ }^{18}$.

\subsubsection{Loja}

A Loja do Masp estava localizada no primeiro subsolo do edifício, próximo à entrada da sala Clemente de Faria, e estava atendendo de terças a domingos das $10 \mathrm{~h}$ às 17h30, e às quintas-feiras até às $19 \mathrm{~h} 30$.

A Loja do MASP estava apresentando livros de arte, de editoras como Taschen, Paisagem, Icon, Cosac\&Naify, Instituto Lina Bo e P.M. Bardi, entre outros. Estava

\footnotetext{
${ }^{12}$ MASP - Museu de Arte de São Paulo. Sobre o Masp.

${ }^{13}$ MASP - Museu de Arte de São Paulo. Sobre o Masp.

${ }^{14}$ MASP - Museu de Arte de São Paulo. Sobre o Masp.

${ }^{15}$ MASP - Museu de Arte de São Paulo. Sobre o Masp.

${ }^{16}$ MASP - Museu de Arte de São Paulo. Sobre o Masp.

${ }^{17}$ MASP - Museu de Arte de São Paulo. Sobre o Masp.

${ }^{18}$ MASP - Museu de Arte de São Paulo. Sobre o Masp.
} 
oferecendo também títulos das editoras Companhia das Letras, Jorge Zahar e H. F. Ullmann, além de uma grande variedade de livros educativos para crianças, como os títulos da Companhia das Letrinhas.

Devido à mudança na gestão administrativa do museu, alguns objetos de prata e em cerâmica assinadas por artistas brasileiros, como as peças de Norma Tamaoki, única artista autorizada a produzir peças com obras de Tarsila do Amaral, e as de Kimi Nii, cujas cerâmicas também estavam à venda na loja do Museu de Arte Moderna de Nova York foram retiradas da loja ${ }^{19}$. Havia também itens de papelaria, em que os mais procurados pelos visitantes eram cartões postais, marcadores de páginas e pôsteres com as obras da Coleção do Masp. O Quadro 3 apresenta os produtos oferecidos neste atrativo:

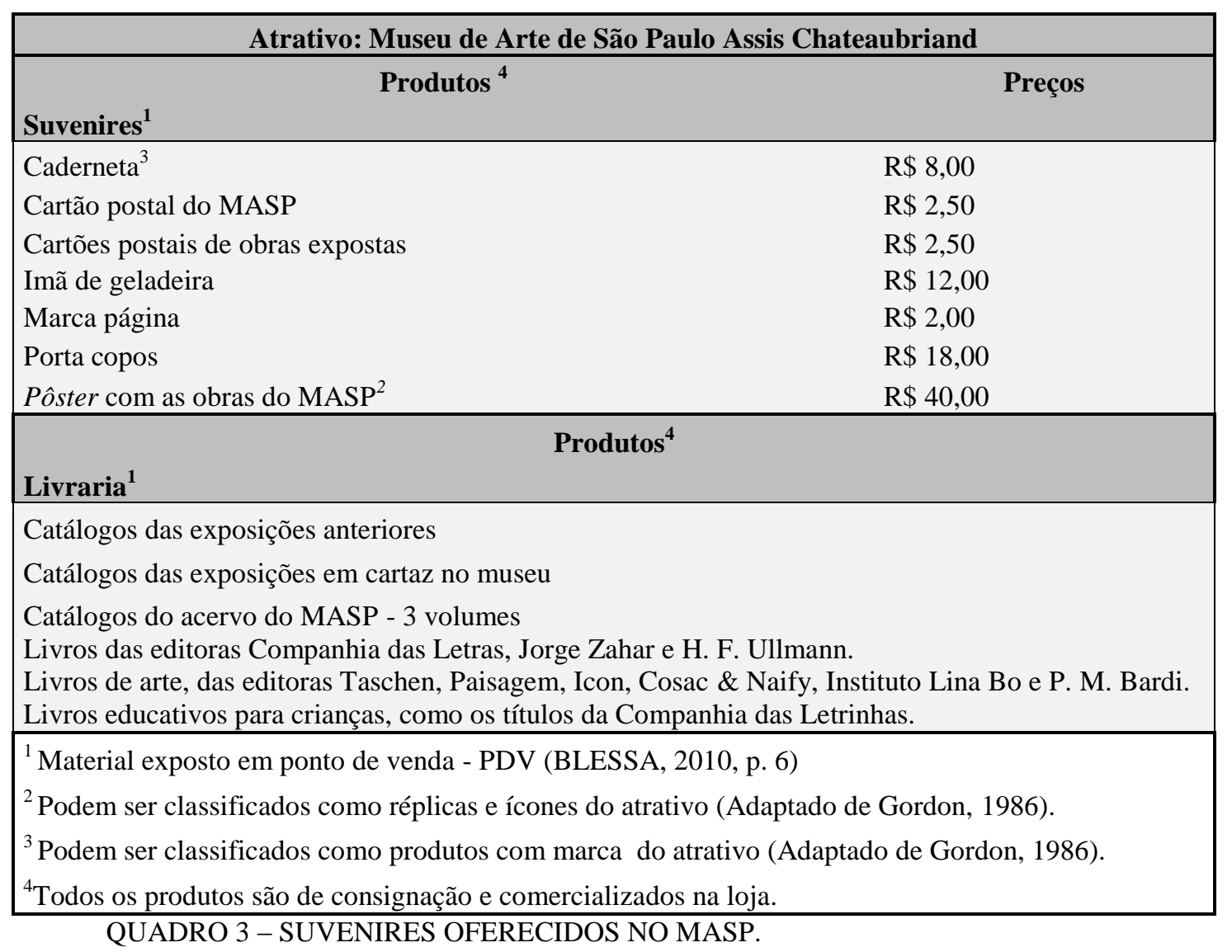

${ }^{19}$ MASP - Museu de Arte de São Paulo. Sobre o Masp. 


\subsection{MUSEU DO FUTEBOL}

Mais do que sobre esporte, o Museu do Futebol é, antes de tudo, um museu sobre a história do povo brasileiro. Instalado o Estádio Municipal Paulo Machado de Carvalho - mais conhecido como Estádio do Pacaembu, localizado em frente à Praça Charles Miller, em São Paulo ${ }^{20}$. A iniciativa foi do Governo do Estado e da Prefeitura de São Paulo - por meio da Secretaria Municipal de Esportes e da São Paulo Turismo com concepção e realização da Fundação Roberto Marinho. A concepção inicial do Museu do Futebol reuniu de forma integrada as três dimensões que constituem um museu: arquitetura, museografia e conteúdo. Interligados, cada conceito teve um papel fundamental no projeto ${ }^{21}$.

Instalado em uma área de $6.900 \mathrm{~m}^{2}$, o Museu do Futebol estava preservando em suas linhas originais um imponente patrimônio público e revelando a arquitetura do Pacaembu ${ }^{22}$. A escolha do estádio foi alinhada do ponto de vista arquitetônico e urbanístico porque preserva, recupera e dá novo uso a um edifício já existente.

\subsubsection{Loja}

Os produtos da loja Futebol SuperStore variavam de camisas de times nacionais e internacionais, blusas, shorts e camisetas personalizados, até bolas, bonés, chinelos, acessórios como cartões do museu em 3D e mini taças banhadas a ouro. Realmente verificou-se uma variedade de produtos ligados ao futebol. Seu horário de funcionamento estava sendo das $9 \mathrm{~h}$ às $18 \mathrm{~h}$, de terça a domingo.

No Quadro 4, foi apresentado os produtos oferecido no atrativo e o preço de venda:

\footnotetext{
${ }^{20}$ MUSEU DO FUTEBOL. Institucional.

${ }^{21}$ MUSEU DO FUTEBOL. Institucional.

${ }^{22}$ MUSEU DO FUTEBOL. Institucional.
} 


\begin{tabular}{|c|c|}
\hline \multicolumn{2}{|c|}{ ATRATIVO: MUSEU DO FUTEBOL } \\
\hline Produtos ${ }^{1}$ & Preços \\
\hline \multicolumn{2}{|l|}{ Acessórios/Suvenir } \\
\hline Bolas & $\mathrm{R} \$ 39,90$ \\
\hline Bonés & $\mathrm{R} \$ 36,90$ \\
\hline Cachecol & $\mathrm{R} \$ 49,99$ \\
\hline Canetas $^{3}$ & $\mathrm{R} \$ 5,00$ \\
\hline Capa de chuva ${ }^{3}$ & $\mathrm{R} \$ 10,00$ \\
\hline Cartão 3D do museu ${ }^{3}$ & $\mathrm{R} \$ 10,00$ \\
\hline Chaveiros de metal $^{3}$ & $\mathrm{R} \$ 10,00$ \\
\hline Chinelos & $\mathrm{R} \$ 34,90$ \\
\hline Garrafas de agua $^{3}$ & $\mathrm{R} \$ 30,00$ \\
\hline Imãs de geladeira $^{3}$ & $\mathrm{R} \$ 5,00$ \\
\hline Lápis ${ }^{3}$ & $\mathrm{R} \$ 3,00$ \\
\hline Livros & $\mathrm{R} \$ 24,90$ \\
\hline Malas & $\mathrm{R} \$ 89,90$ \\
\hline Maquetes (arenas: Corinthians, Morumbi e Palmeiras) ${ }^{2}$ & $\mathrm{R} \$ 89,99$ \\
\hline Mini réplicas da taça ${ }^{2}$ & $\mathrm{R} \$ 100,00$ \\
\hline Mochilas & $\mathrm{R} \$ 50,00$ \\
\hline Xícaras $^{3}$ & $\mathrm{R} \$ 15,00$ \\
\hline \multicolumn{2}{|l|}{ Produtos $^{1}$} \\
\hline Vestuário $^{4}$ & Preços (a partir) \\
\hline Shorts & $\mathrm{R} \$ 39,90$ \\
\hline Agasalhos & $\mathrm{R} \$ 189,00$ \\
\hline Camisetas de time nacionais e internacionais personalizadas & $\mathrm{R} \$ 165,99$ \\
\hline Camisetas de times nacionais e internacionais & $\mathrm{R} \$ 149,99$ \\
\hline Chuteiras & $\mathrm{R} \$ 165,99$ \\
\hline Meias & $\mathrm{R} \$ 24,99$ \\
\hline \multicolumn{2}{|c|}{${ }^{1}$ Material exposto em ponto de venda - PDV (BLESSA, 2010, p. 6) } \\
\hline \multirow{3}{*}{\multicolumn{2}{|c|}{$\begin{array}{l}2 \text { Podem ser classificados como réplicas e ícones do atrativo (Adaptado de Gordon, 1986). } \\
{ }^{3} \text { Podem ser classificados como produtos com marca do atrativo (Adaptado de Gordon, 1986). } \\
{ }^{4} \text { Marcas disponíveis: Nike, Adidas, Umbro, Penalty, Puma e Marc4. }\end{array}$}} \\
\hline & \\
\hline & \\
\hline \multicolumn{2}{|c|}{ Todos os produtos são comercializados na loja e no site Futebol SportStore. } \\
\hline
\end{tabular}

QUADRO 4 - SUVENIRES OFERECIDOS NO MASP.

\subsection{PINACOTECA DO ESTADO DE SÃO PAULO}

A Pinacoteca do Estado é um museu de artes visuais, com ênfase na produção brasileira do século XIX até a contemporaneidade ${ }^{23}$. Fundada em 1905 pelo Governo do

${ }^{23}$ PINACOTECA DO ESTADO DE SÃO PAULO. Institucional. 
Estado de São Paulo, estava sendo o museu de arte mais antigo da cidade ${ }^{24}$. Estava instalada no antigo edifício do Liceu de Artes e Ofícios, projetado no final do século XIX pelo escritório do arquiteto Ramos de Azevedo, que sofreu uma ampla reforma com projeto do arquiteto Paulo Mendes da Rocha, no final da década de $1990^{25}$.

A Pinacoteca estava realizando cerca de 30 exposições e recebendo aproximadamente 500 mil visitantes a cada $a^{26}{ }^{26}$. O primeiro andar estava recebendo as exposições temporárias e o segundo sendo dedicado à mostra de longa duração de um acervo brasileiro. A área central estava abrigando o Projeto Octógono Arte Contemporânea, e no térreo se situando as áreas técnicas, o auditório e a cafeteria ${ }^{27}$. Desde 2006 estava sendo administrada pela APAC - Associação Pinacoteca Arte e Cultura (PINACOTECA, 2014).

\subsubsection{Loja}

A loja presente dentro da Pinacoteca estava localizada no primeiro piso, estrategicamente na saída do museu além de estar presente em forma de exposição pelo museu. Apresentava uma grande variedade de produtos com a marca do museu e com referência as obras em exposição. Também estava oferecendo livros de diversas editoras. Toda a arrecadação estava sendo destinada a manutenção do acervo e do museu $^{28}$.

No Quadro 5 abaixo, foi apresentado os produtos oferecido no atrativo e o preço de venda:

\footnotetext{
${ }^{24}$ PINACOTECA DO ESTADO DE SÃO PAULO. Institucional.

${ }^{25}$ PINACOTECA DO ESTADO DE SÃO PAULO. Institucional.

${ }^{26}$ PINACOTECA DO ESTADO DE SÃO PAULO. Institucional.

${ }^{27}$ PINACOTECA DO ESTADO DE SÃO PAULO. Institucional.

${ }^{28}$ PINACOTECA DO ESTADO DE SÃO PAULO. Institucional.
} 


\section{ATRATIVO: PINACOTECA DO ESTADO DE SÃO PAULO}

\section{Suvenir $^{3}$}

Produtos $^{1}$

Preços (a partir)

Coleção Joias do Acervo - anel, brinco, pulseira e colar

$\mathrm{R} \$ 420,00$

Quebra cabeça 500

$\mathrm{R} \$ 25,00$

Quebra cabeça 1000 peças

$\mathrm{R} \$ 30,00$

Documentário Arte no Brasil - DVD em 3 idiomas

$\mathrm{R} \$ 35,00$

Avental

$\mathrm{R} \$ 55,00$

Nécessaire

$\mathrm{R} \$ 40,00$

Camiseta

$\mathrm{R} \$ 48,00$

Mochila

$\mathrm{R} \$ 30,00$

Boné

$\mathrm{R} \$ 22,00$

Cartão postal 15X21

$\mathrm{R} \$ 3,00$

Cartão postal 10X15

$\mathrm{R} \$ 2,00$

Bolsa $^{23}$

$\mathrm{R} \$ 50,00$

Jogo de baralho

$\mathrm{R} \$ 25,00$

Cadernos com foto das obras

$\mathrm{R} \$ 39,00$

Bloco de anotações com obras de artistas

$\mathrm{R} \$ 18,00$

Bloco de anotações com obras dos artistas pequenos

$\mathrm{R} \$ 8,00$

Imas de geladeira com obras dos artistas

$\mathrm{R} \$ 5,00$

Gravuras motivo

$\mathrm{R} \$ 300,00$

Livros para crianças

$\mathrm{R} \$ 28,00$

Gravura comemorativa Leonilson

$\mathrm{R} \$ 3.300,00$

Caneca

$\mathrm{R} \$ 20,00$

Copo

$\mathrm{R} \$ 18,00$

Xícaras

$\mathrm{R} \$ 23,00$

Guarda chuvas

$\mathrm{R} \$ 80,00$

Lápis

$\mathrm{R} \$ 2,50$

Quadros $^{2}$

$\mathrm{R} \$ 350,00$

Cartões postais com obras dos artistas

$\mathrm{R} \$ 2,00$

Borrachas

$\mathrm{R} \$ 3,00$

Chaveiro de metal

$\mathrm{R} \$ 15,00$

Estojos

$\mathrm{R} \$ 18,00$

Diversos livros sobre arte, arquitetura, outros

$\mathrm{R} \$ 5,00$

\section{Produtos $^{1}$}

Livraria $^{3}$

Preços (a partir)

Livros de arte

$\mathrm{R} \$ 22,00$

Livros infantis

$\mathrm{R} \$ 26,90$

Livros de arquitetura

$\mathrm{R} \$ 42,00$

Catalago das exposições ${ }^{2}$

$\mathrm{R} \$ 5,00$

Continua... 
Continuação...

\footnotetext{
${ }^{1}$ Material exposto em ponto de venda - PDV (BLESSA, 2010, p. 6).

${ }^{2}$ Podem ser classificados como réplicas e ícones do atrativo (Adaptado de Gordon, 1986).

${ }^{3}$ Podem ser classificados como produtos com marca do atrativo (Adaptado de Gordon, 1986).

Todos os produtos são consignados e a renda é revertida para a manutenção do museu
} QUADRO 5 - SUVENIRES OFERECIDOS NA PINACOTECA.

\subsection{ANÁLISE GERAL DAS LOJAS: Estrutura}

As lojas estavam seguindo padrões semelhantes no formato de material de ponto de venda para expor os produtos. Também estando localizadas em pontos estratégicos dentro dos atrativos.

\subsubsection{Administração consignados}

Entende-se por administração consignada, segundo as informações prestadas nos estabelecimentos, a venda de produtos que foram incluídos a marca do atrativo para a venda. Também existe um grande número de livros que foram doados para a venda. Verificou-se existir pontos positivos e negativos em relação à consignação. Como pontos positivos pode-se listar os custos zero para o atrativo e o retorno total, o qual estava sendo destinado a manutenção do museu. Entretanto, a singularidade dos produtos, principalmente os que apresentavam a marca do atrativo se apresentou bastante semelhante.

\section{CONSIDERAÇÕES FINAIS}

Após o levantamento dos produtos oferecidos nos principais atrativos turísticos - "Vale a Viagem", considerou-se ter ficado evidente a presença de produtos com a marca do próprio atrativo e de produtos com referência aos artistas e obras expostas nos mesmos. Verificou-se que o formato das lojas, tipo consignação, presente no Masp e Pinacoteca, limitavam a oferta a produtos que imprimiam a marca do atrativo e não do destino em questão, a cidade de São Paulo. Entretanto, não se teria como negar que um suvenir com a marca do atrativo não caracterizasse a cidade ou que uma camiseta do 
Brasil, personalizada ou simples, não caracterizasse um suvenir (porém, não era algo singular do atrativo, tampouco da cidade).

O Catavento estava tendo sua oferta de suvenires realizada pela empresa Ciência Prima, a qual estava reproduzindo os experimentos do museu em tamanho menor, além de oferecer palestras e eventos a inúmeras escolas que visitavam o local. A variedade da loja não era grande, entretanto era possível comprar pelo site da empresa.

Nos museus Pinacoteca e Masp, as lojas estavam destinadas a manutenção direta do atrativo. Já nos casos do Catavento e do Museu do Futebol as lojas eram terceirizadas pelo atrativo e não se limitavam ao atrativo.

Os materiais como livros e DVD's estavam voltados para as exposições vigentes e anteriores. Com exceção do Museu do Futebol, todos os atrativos estavam oferecendo livros infantis, de diversas editoras, devido a grande procura do público com crianças (mesmo não tendo relação com o atrativo, com o destino, com o acervo ou exposições). A presença desses elementos estava se dando pelo significado que os pais atribuíam a compra desses títulos na loja do museu.

Considera-se não haver dúvidas de que destinos como Londres - com seus ônibus -, Rio de Janeiro - com seus cristos em miniatura ou as calçadas de Copacabana -, Paris - com a Torre Eiffel -, ou Mato Grosso com suas araras, são facilmente reconhecidos como seus suvenires. Porém, metrópoles como São Paulo, apresentam algumas singularidades, como o próprio Masp (o mais importante museu de arte ocidental do Hemisfério Sul e dono do edifício cartão postal da cidade).

Souza e Carvalho (2014) sinalizam que, a construção de uma imagem distante da realidade local com a finalidade de torná-la mais atrativa pode ocasionar na promoção de uma imagem falsa, não ajustada a identidade daquele local ou daquela população. Para Beni (2001 ${ }^{29}$, apud SOUZA; CARVALHO, 2014, p. 75) a promoção da imagem turística condizente com a identidade local, pode ser exatamente o que irá diferenciá-la de outras destinações.

De acordo com o referencial teórico, o suvenir resgata memórias vividas, transforma o intangível no tangível, guardando uma alegoria de significados e experiências. Sendo assim, os produtos presentes nas lojas dos atrativos se tornam

${ }^{29}$ BENI, M. C. Análise estrutural do turismo. São Paulo: Senac, 2006. 
importantes para compor a imagem da cidade, pois eles já estavam compondo a imagem do atrativo.

Finalizando, julga-se importante mencionar que o número de pesquisas voltadas para suvenir ainda é pequeno comparado a outros temas relacionados ao turismo. Entretanto, é preciso pesquisas cada vez mais densas com relação à percepção de gestores e dos próprios turistas sobre o tema.

\section{REFERÊNCIAS}

ARAGÃO, I. R.; SILVA FILHO, J. T. da. Lugares de Memória e Turismo Religioso: a Presença de Irmã Dulce em São Cristóvão Sergipe-Brasil (1933-1934). Turismo \& Sociedade. Curitiba, v. 8, n. 3, p. 401-418, setembro-dezembro de 2015.

BENI, M. C. Análise estrutural do turismo. São Paulo: Senac, 2006.

BLESSA, R. Merchandising no Ponto-de-venda. 5. ed. São Paulo: Atlas, 2010.

BRASIL (Ministério do Turismo). Plano Nacional do Turismo - PNT: Uma Viagem de Inclusão, Ministério do Turismo. Disponível em: <http://www.turismo.gov.br/turismo/o_ministerio/plano_nacional/index.html>. Acesso em: 10/01/2014.

BRASIL. Ministério do Turismo. Turismo no Brasil 2010. Brasília/DF: MTUR, 2010.

CATAVENTO CULTURAL E EDUCACIONAL. Institucional. Disponível em: $<$ http://www.cataventocultural.org.br/>. Acesso em: 20/11/2014.

CIÊNCIA PRIMA. Fonte: <http://www.cienciaprima.com.br/>.

DICIONÁRIO ONLINE AURÉLIO. Suvenir. Disponível em: <www.dicionarioonlineaurelio.com.br>. Acesso em: 12/11/2014.

FUTEBOL SUPER STORE. Fonte: <http://www.superstore.com.br/>.

GORDON, B. The Souvenir: Messenger of The Extraordinary. Journal of Popular Culture, 20 (3), p. 135- 146, 1986.

GUIA QUATRO RODAS. Editora Abril, 2014.

HORODYSKI, G. S. O Consumo na Experiência Turística: o caso dos souvenirs no destino Curitiba-PR. Tese de Doutorado. Programa de Pós-Graduação em Geografia, Universidade Federal do Paraná. Curitiba, 2014. 
HORODYSKI, G. S; MANOSSO, F. C; GANDARA, J. M. Conceitos e Abrangência do suvenir na dinâmica do espaço turístico: O Caso de Curitiba-PR. Revista Turismo Visão e Ação, 2013. v. 15, n. 1, p. 130-143.

HORODYSKI, G. S; MANOSSO, F. C; GANDARA, J. M. O Consumo de suvenires a experiência turística em Curitiba (PR). Caderno Virtual de Turismo. Rio de Janeiro, v. 12, n. 3, p. 323-342, dez. 2012.

HORODYSKI, G. S; MANOSSO, F. C; GANDARA, J. M. A pesquisa narrativa na investigação das experiências turísticas relacionadas ao consumo de suvenir: uma abordagem fenomenológica. $5^{\circ}$ CONGRESSO LATINO-AMERICANO DE INVESTIGAÇÃO TURÍSTICA. V. 25, n. 1, abril 2014.

IBGE. INSTITUTO BRASILEIRO DE GEOGRAFIA E ESTATÍSTICA. Censo Demográfico 2000.

LOHMAnn, G; PANOSSO NETTO, A. Teoria do Turismo: conceitos, modelos e sistemas. São Paulo: Aleph, 2008.

LOVE, L. L.; SHELDON, P. R. Souvenirs: messengers of meaning. Revista Advances in Consumer Research, V. 25, Association for Consumer Research, Provo, UT, pp. 170-5, 1998. Disponível em: <http://onlinelibrary.wiley.com/doi/10.1111/j.00223840.1986.2003_135.x/abstract>. Acesso: fev 2011.

MACHADO, P. de S; SIQUEIRA, E. D. de. TURISMO, CONSUMO E CULTURA: significados e usos sociais do suvenir em Petrópolis - RJ. Bahia: Comunicação e Cultura, v. 10, 12 out. 2014.

MAFFESOLI, M. Le temos des tribus. Le déclin de l'individualisme dans les sociétes postmodernes. Paris: La Table Ronde, 2005.

MAM. Museu de Arte Moderna de São Paulo. Quem somos. Disponível em: <http://mam.org.br/institucional/>.

MASP. Museu de Arte de São Paulo. Sobre o Masp. Disponível em: <http://masp.art.br/masp2010/index.php>. Acesso em: 20/11/2014.

MEDEIROS, B. F; CASTRO, C. A CIDADE E SEUS SUVENIRES: O Rio de Janeiro para o turista ter. São Paulo: Anptur, v. 1, n. 1, 12 out. 2014. Revista Brasileira de Pesquisa em Turismo.

MORGAN, N; PRITCHARD, A. On Souvenires and Metonymy: Narratives of memory, metaphor and materiality. Tourist Studies, v. 5, n. 1, 2005, p. 29-53.

MUSEU DO FUTEBOL. Institucional. Disponível em: <http://museudofutebol.org.br/bar-e-loja/>. Acesso em: 15/11/2014.

NETTO, A. P. Filosofia do Turismo: Teoria e epistemologia. São Paulo, Aleph, 2005. 
PINACOTECA DO ESTADO DE SÃO PAULO. Institucional. Disponível em: $<$ http://www.pinacoteca.org.br>. Acesso em: 20/11/2014.

PREFEITURA DE SÃO PAULO. Fonte: <http://capital.sp.gov.br/>.

SÃO PAUlO TURISMO S/A. Site Oficial de Turismo da cidade de São Paulo. Disponível em:

<http://www.cidadedesaopaulo.com/sp/br/o-que-visitar/atrativos $>$ Acesso em: $12 / 10 / 2014$.

SOUZA, A. M; CARVALHO, A. N. de. O comércio de suvenires e sua relação com a imagem da destinação: um estudo na cidade de Itu/SPPDF. Revista Hospitalidade, São Paulo, v. 11, n. 1, p. 64-89, 2014.

SWANSON, K. Tourist's and Retailer's Perceptions of Souvenirs. Journal of Vacation Marketing. N. 10, v. 363, 2004.

THEOBALD, W. Turismo Global. 2. ed. São Paulo: Saraiva, 2002.

VISITE SÃO PAULO. Dados da cidade. Disponível em: <http://www.visitesaopaulo.com/dados-da-cidade.asp>. Acesso em: 12/10/2014.

Recebido em: 10-11-2016.

Aprovado em: 10-12-2016. 